\title{
DESSECAÇÃO DE SEMENTES DE Achras sapota L. ${ }^{1}$
}

\author{
NADJAMA BARRETO DO PRADO², EUSÍNIA LOUZADA PEREIRA ${ }^{3}$, \\ ABEL REBOUÇAS SÃO JOSÉ 4
}

RESUMO-A perda da viabilidade das sementes das espécies está diretamente relacionada com a tolerância à dessecação, que é avaliada a partir da determinação do teor de água mínimo suportável pelos tecidos das sementes. Diante disso, o objetivo deste trabalho foi avaliar os efeitos da dessecação em sementes de Achras sapota L. O experimento foi desenvolvido no Laboratório de Fitotecnia da Universidade Estadual de Santa Cruz, Bahia, e os tratamentos consistiram na avaliação da emergência e vigor das sementes submetidas à dessecação de aproximadamente $5 \%$ do teor de água a partir do grau de umidade inicial (36\%) até atingir $7 \%$. Diante dos resultados obtidos, concluiu-se que as sementes de $A$. sapota L. podem ser dessecadas até atingirem o teor de água de $16 \%$, sem comprometimento da viabilidade das sementes e do desenvolvimento de plântulas normais.

Termos para indexação: condutividade elétrica, secagem, viabilidade, vigor.

\section{DESICCATION OF Achras sapota L. SEEDS}

ABSTRACT - The loss of seed viability of species is directly related to desiccation tolerance, which is evaluated by determining the minimum water content of seed tissues. Therefore, the objective of this study was evaluating the effects of desiccation on Achras sapota L. seeds quality. The study was developed at Plant Science Laboratory, in Santa Cruz State University, State of Bahia, Brazil, and the treatments consisted in determining the emergence and vigor of seeds exposed to desiccation of approximately $5 \%$ water content from the initial moisture content of $36 \%$ until $7 \%$. Based on these results it was concluded that the seeds of $A$. sapota L. can be desiccated until they reach the water content of $16 \%$ without compromising seed viability and development of normal seedlings.

Index terms: electrical conductivity, drying, feasibility, vigor.

\section{INTRODUÇÃO}

A Achras sapota L. é uma espécie frutífera de porte arbóreo pertencente à família Sapotaceae, originária da América Central. De clima tropical e subtropical, adaptou-se muito bem no Brasil, sendo cultivada desde as faixas subtropicais de São Paulo até a Floresta Tropical Úmida da Região Amazônica, como também no litoral e serras Nordestinas, onde as condições climáticas são bastante favoráveis ao seu desenvolvimento e produção (GOMES, 2007). Os frutos dessa espécie são conhecidos popularmente como sapoti e sapota, a depender da cultivar, podendo ser comercializados in natura ou processados devido a sua polpa ser suculenta, doce e sem fibras, tendo uma ótima aceitação no mercado (GOMES, 2007). Quanto à propagação, a sapota pode ser multiplicada por enxertia ou diretamente por sementes, dando origem a porta-enxerto (GOMES, 2007). O conhecimento prévio do comportamento fisiológico das sementes durante os procedimentos de secagem e armazenamento é imprescindível para a preservação ex situ de germoplasma e seu uso sustentável (FARRANT, 2010; PRITCHARD et al., 2004). Dessa forma, as sementes podem ser classificadas como ortodoxas, intermediárias e recalcitrantes. As sementes ortodoxas são tolerantes à dessecação a baixos conteúdos de umidade (geralmente $5 \%$ ) e podem ser armazenadas sob baixas temperaturas por um longo período. No entanto, as sementes recalcitrantes não toleram desidratação abaixo de 20-30\% de umidade, enquanto as intermediárias são sensíveis à dessecação e não sobrevivem a níveis de desidratação abaixo de $10 \%$ de umidade (HONG; ELLIS, 1996). Cruz e Carvalho (2003) concluíram que as sementes de curupixá (Micropholis cf.

${ }^{1}$ (Trabalho 249-13). Recebido em: 01-08-2013. Aceito para publicação em: 09-09-2014.

${ }^{2}$ MSc Produção Vegetal - Universidade Estadual do Sudoeste da Bahia - E-mail:nadjamaprado@yahoo.com.br

${ }^{3}$ DSc Fitotecnia - Prof ${ }^{a}$ Visitante no Programa de Pós-Graduação Mestrado em Produção Vegetal - Universidade Estadual do Sudoeste da Bahia - E-mail:eusinialp@yahoo.com.br

${ }^{4}$ DSc Agronomia, Prof ${ }^{\circ}$ Titular/Pleno Universidade Estadual do Sudoeste da Bahia - E-mail: abeljose3@gmail.com 
venulosa Mart. \& Eichler) se enquadram no grupo das recalcitrantes, pois quando foram dessecadas em recipiente contento sílica gel, por um período de 72 e 96 horas, apresentaram 24,7\% de germinação, enquanto as sementes recém-extraídas do fruto apresentaram $55 \%$ de germinação. A mesma sensibilidade à dessecação foi observada por Cabral et al. (2013), em sementes de outra espécie da família sapocaceae, a guapeva (Pouteria garneriana Radlk.). Os autores constataram que a viabilidade das sementes de guapeva é comprometida quando o teor de água é reduzido de $41,71 \%$ para valores abaixo de $30 \%$. Diante da escassez de informações a respeito do assunto, o presente trabalho tem como objetivo avaliar os efeitos imediatos da desidratação sobre a qualidade fisiológica das sementes de $A$. sapota $\mathrm{L}$. visando à conservação de suas sementes.

\section{MATERIAL E MÉTODOS}

Os frutos de Achras sapota foram provenientes de plantas da cultivar IPA 180 , denominada chocolate, oriundos da Fazenda Planalto, em

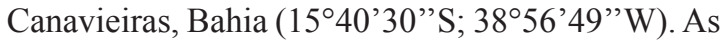
sementes foram submetidas ao processo de assepsia, sendo imersas em uma solução de álcool a 70\%, por 1 minuto, lavadas três vezes em água destilada, em seguida imersas em solução comercial de água sanitária por três minutos e novamente lavadas três vezes com água destilada. Por fim foram imersas em solução de nistatina (fungicida) a $1 \%$, por 10 minutos. Passado esse tempo, foram lavadas três vezes. Após a assepsia, as sementes foram colocadas para secar, por uma hora, sobre papel toalha para a remoção da água superficial, sob temperatura ambiente. Ambos os processos foram realizados em capela de fluxo laminar. Depois foram distribuídas sobre bandeja de malha de alumínio medindo 32 x $32 \mathrm{~cm}$ e acondicionadas em estufa de circulação forçada de ar, mantida à temperatura de $30 \pm 2^{\circ} \mathrm{C}$. Aproximadamente, a cada decréscimo de 5\% na massa de sementes, as mesmas foram amostradas para avaliação da viabilidade, até atingir $7 \%$ de umidade (MASETTO et al., 2008). A estimativa do conteúdo de água foi realizada pela diferença de massa, Mf $=\mathrm{Mi}(100-\mathrm{Ui}) / 100-\mathrm{Uf}$, em que: Mf = massa da amostra $(\mathrm{g})$ após a secagem; $\mathrm{Mi}=$ massa da amostra $(\mathrm{g})$ antes da secagem; $\mathrm{Ui}=$ teor de água (\%) antes da secagem; Uf = grau de umidade (\%) desejado após a secagem (CROMARTY et al., 1985). À medida que foram sendo atingidos os teores de água desejados, as amostras foram homogeneizadas e subdivididas para a determinação do grau de umidade e os seguintes testes: a) Grau de umidade-determinado através do método da estufa (temperatura de $105^{\circ} \mathrm{C}$ $\pm 2^{\circ} \mathrm{C} / 24$ horas), sendo utilizadas quatro repetições de 10 sementes (BRASIL, 2009); b) Condutividade elétrica - foram utilizadas quatro repetições de 50 sementes, pesadas (precisão de $0,0001 \mathrm{~g}$ ) e colocadas em copos plásticos contendo $75 \mathrm{~mL}$ de água destilada autoclavada e mantidas em incubadora do tipo B.O.D. a $25^{\circ} \mathrm{C}$, por 24 horas (KRZYZANOWSKI et al., 1999); c) Emergência de plântulas - foram semeadas quatro repetições de 50 sementes, numa profundidade de $2,5 \mathrm{~cm}$ em jardineiras de polietileno contendo substrato areia autoclavada, umedecida com $60 \%$ de a sua capacidade de retenção de água, e mantidas em ambiente de laboratório sob temperatura média de $25^{\circ} \pm 2^{\circ} \mathrm{C}$. Ao final do teste (44 dias após a semeadura), quando as plântulas apresentaram o primeiro par de folhas definitivas, foram removidas do substrato e computada a porcentagem de plântulas normais (plântulas que apresentavam todas as suas estruturas essenciais bem desenvolvidas e completas) e plântulas anormais (BRASIL, 2009); d) Primeira contagem do teste de emergência - como para a espécie em questão não existe uma prescrição na RAS nem em artigos referenciando o início da germinação, adotou-se a observação da emergência no substrato, que ocorreu no décimo oitavo dia após a semeadura, e a retirada das plântulas para serem avaliadas quanto à normalidade e recolocadas no substrato (VIEIRA; CARVALHO, 1994); e) Tempo médio de emergência - foi calculado empregando-se a equação $\mathrm{t}_{\text {médio }}=\sum \mathrm{n}_{\mathrm{i}} \cdot \mathrm{t}_{\mathrm{i} /} \sum \mathrm{n}_{\mathrm{i},}$ em que: $\mathrm{n}_{\mathrm{i}}$ representa o número de sementes germinadas dentro de um intervalo de tempo $t_{i-1}$ e $t_{i}$ (FERREIRA; BORGHETTI, 2004); f)

Comprimento de plântulas - realizado ao final do teste de emergência, mensurando o comprimento total das plântulas normais, tomando-se a medida da ponta da raiz principal até a inserção dos cotilédones (KRZYZANOWSKI et al., 1999); e g) Massa seca de plântulas - as plântulas normais foram colocadas em sacos de papel e levadas para secar em estufa de circulação forçada de ar regulada a $80^{\circ} \mathrm{C}$, durante 24 horas. Os resultados foram expressos em mg/plântula (KRZYZANOWSKI et al., 1999).O delineamento experimental adotado foi o inteiramente casualizado, com sete tratamentos (teor de água) e quatro repetições. Verificou-se pelos testes de Lilliefors para normalidade e de Bartlett para homogeneidade, a necessidade de transformação dos dados, sendo utilizados arco-seno $V_{\mathrm{X}} / 100$ para as variáveis com dados expressos em porcentagem, e $\log (\mathrm{x}+1)$ para os decimais. Os dados normais foram submetidos à análise de variância, e os que não seguiram distribuição normal foram submetidos ao teste não paramétrico de Kruskal-Wallis (TABELA 2). As 
médias das variáveis que apresentaram resultados significativos foram ajustadas aos modelos de regressão e adequados seus valores aos calculados pela equação obtida pela regressão. Posteriormente, calcularam-se os coeficientes de correlação simples de Pearson ( $\mathrm{r}$ ) entre as variáveis que apresentaram distribuição normal.

\section{RESULTADOS E DISCUSSÃO}

O teor de água inicial das sementes de A. sapota foi de $36 \%$, e a redução desse teor foi relativamente rápida nos primeiros pontos de dessecação (29; 22; 18 e 16\%), levando pouco mais de 24 horas. A partir do teor de água de $16 \%$, observou-se praticamente o dobro do tempo necessário para dessecar as sementes até os valores de 11 e 7\% (FIGURA 1). Resultado semelhante foi observado por Santos et al. (2010), em que o teor de água das sementes de Hancornia speciosa Gomes foi reduzido de $56 \%$ para $12 \%$ após 144 horas de secagem em ambiente de laboratório (temperatura média de $24,5 \pm 0,5^{\circ} \mathrm{C}$ e umidade relativa média de $78 \pm 3 \%$ ). A redução do teor de água das sementes de $A$. sapota para 11 e 7\% influenciou na emergência e no número de plântulas anormais (FIGURAS 2 e 3 ), apresentando os valores médios de 78 e $62,5 \%$ de emergência, 30 e $42 \%$ de plântulas anormais, respectivamente. De acordo com as análises de regressão (FIGURAS 2 e 3), a porcentagem de germinação e o número de plântulas anormais seguiram uma tendência exponencial inversamente proporcional a partir da redução do teor de água das sementes. Portanto, o teor de água crítico para as sementes de $A$. sapota é de $11 \%$, culminando com o aumento da porcentagem de plântulas anormais (FIGURA 3). Oliveira et al. (2011), estudando a dessecação de sementes de Genipa americana L. por 24 horas em ambiente de laboratório (temperatura média de $28^{\circ} \mathrm{C}$ e umidade relativa do ar de $75 \%$ ), observaram máxima emergência de plântulas ( $92 \%)$, quando o teor de água se encontrava acima de $40 \%$. Após este período, diminui-se progressivamente o teor de água comprometendo e até anulando a emergência quando a desidratação atingiu valores abaixo de 5\%. Zucarelli et al. (2009), por sua vez, verificaram em sementes de citrumelo 'Swingle' (Citrus paradisi Macf X Poncirus trifoliata (L) Raf.) redução da porcentagem de germinação de $72 \%$ (grau de umidade de $35 \%$ ) para $40 \%$ e aumento de sementes mortas (44\%) quando foram dessecadas até 13\% de teor de água. Nos gráficos de regressão das variáveis condutividade elétrica, primeira contagem do teste de emergência, comprimento total de plântulas e tempo médio de emergência de plântulas, foi observada uma tendência de diminuição do potencial fisiológico das sementes, a partir da redução do teor de água das sementes (FIGURAS 04, 05, 06 e 07), exceto para variável massa seca de plântulas. Os resultados médios das variáveis condutividade elétrica e comprimento total de plântulas seguiram a tendência exponencial com valores inversamente proporcionais à redução do teor de água das sementes. Os valores médios obtidos na primeira contagem, calculados pela equação, também seguiram uma tendência exponencial, indicando que sementes frescas e recém-beneficiadas ( $36 \%$ de umidade) promoveram maior número de plântulas emergidas na primeira contagem, quando comparado às sementes que foram dessecadas. Os resultados obtidos demonstram que a secagem afetou a viabilidade e o vigor das sementes, como constatado nos testes de emergência e primeira contagem de plântulas (FIGURAS 2 e 5). A redução progressiva do teor de água das sementes resultou na emergência tardia, levando assim maior tempo para atingirem o estádio de plântula, refletindo nos resultados do tempo médio de emergência (FIGURA 7). Esse comportamento corresponde à média do tempo necessário para um conjunto de sementes emergirem, inferindo que o menor tempo para a formação das plântulas normais (24 dias) foi proveniente de sementes frescas com teor de água inicial inalterado (36\%). No entanto, a redução do teor de água das sementes para $7 \%$ de umidade ocasionou maior tempo para a emergência de plântulas (44 dias) (FIGURA 7). A diminuição no vigor das sementes de $A$. sapota ocorreu devido à redução do grau de umidade das sementes, pois de acordo com os resultados da condutividade elétrica (FIGURA 4), a diminuição do teor de água das sementes promoveu aumento da quantidade de lixiviados. Esses resultados estão de acordo com Walters (2000), quando afirma que a perda de água expõe os sítios macromoleculares à ação de radicais livres que promovem, consequentemente, a perda da função ou desestruturação das macromoléculas e membranas celulares, alterando sua integridade funcional e estrutural. Os efeitos da dessecação sobre o desempenho fisiológico de sementes também foram verificados por Nascimento et al. (2010) sendo que a desidratação progressiva (37,4; 30,$3 ; 26,1 ; 21,0 ; 15,1$ e $11,9 \%$ de água), realizada em estufa de circulação forçada de ar $\left(30 \pm 2^{\circ} \mathrm{C}\right)$, intensificou o processo de deterioração das sementes de Euterpe oleracea Mart., com anulação da germinação, ao atingirem $15 \%$ de teor de água. Na Tabela 1, observa-se que a correlação do teste 
de condutividade elétrica com todas as variáveis analisadas foi altamente significativa, exceto para a variável sementes mortas, a qual não apresentou correlação com a condutividade elétrica, a $5 \%$ de significância. Os dados de condutividade elétrica apresentaram correlação significativa e negativa com as variáveis emergência e primeira contagem, enquanto em relação ao tempo médio de emergência, a correlação foi signficativa e positiva. Destaca-se, também, a correlação significativa e negativa entre a emergência e o tempo médio de emergência. Esses resultados permitem afirmar que o aumento da liberação de solutos das sementes em resposta à menor velocidade de restabelecimento da integridade das membranas celulares reflete na emergência de plântulas, comprovando a confiabilidade da aplicação do teste de condutividade elétrica para demonstrar os danos causados pelo processo de dessecação em sementes de A. sapota. Resultados semelhantes aos obtidos no presente trabalho foram constatados por Martins et al. (2009) durante a avaliação do potencial fisiológico de lotes de sementes de Euterpe oleracea com teor de água de 32,2 a 45,5\%, e os resultados de correlação simples entre condutividade elétrica e os dados de germinação indicaram correlação negativa altamente significativa, ou seja, aumentos nos valores de condutividade elétrica, decorrentes da desestruturação das membranas celulares quando do processo de deterioração, corresponderam à queda da germinação e vigor. Tokuhisa et al. (2009) verificaram que o teste de condutividade elétrica, conduzido sob duas temperaturas $\left(25^{\circ} \mathrm{C}\right.$ e $\left.30^{\circ} \mathrm{C}\right)$, dois volumes de água ( 50 e $75 \mathrm{~mL}$ ) e seis períodos de embebição (2; 4; 6; 8; 24 e 48 horas), apresentou correlação negativa significativa com a emergência de plântulas de Carica papaya L., provenientes de diferentes lotes de sementes, destacando a eficiência do teste para detectar diferenças no potencial fisiológico de diferentes lotes, especialmente quando as sementes são imersas em 50 e $75 \mathrm{~mL}$ de água e $25^{\circ} \mathrm{C}$ e $30^{\circ} \mathrm{C}$, respectivamente. Pouquíssimos são os trabalhos com frutíferas que correlacionam os testes de vigor, mais especificamente o teste de condutividade elétrica, com os dados de germinação ou emergência. Pode ser observada esta comparação em sementes de cereais, como é o caso de sementes de $X$. triticosecale Wittmack triticale) observadas por Steiner et al. (2011) que viram correlação negativa significativa entre os testes de condutividade elétrica e a germinação, e correlação positiva significativa entre o teste de condutividade elétrica com quase todos os testes de vigor utilizados no experimento.

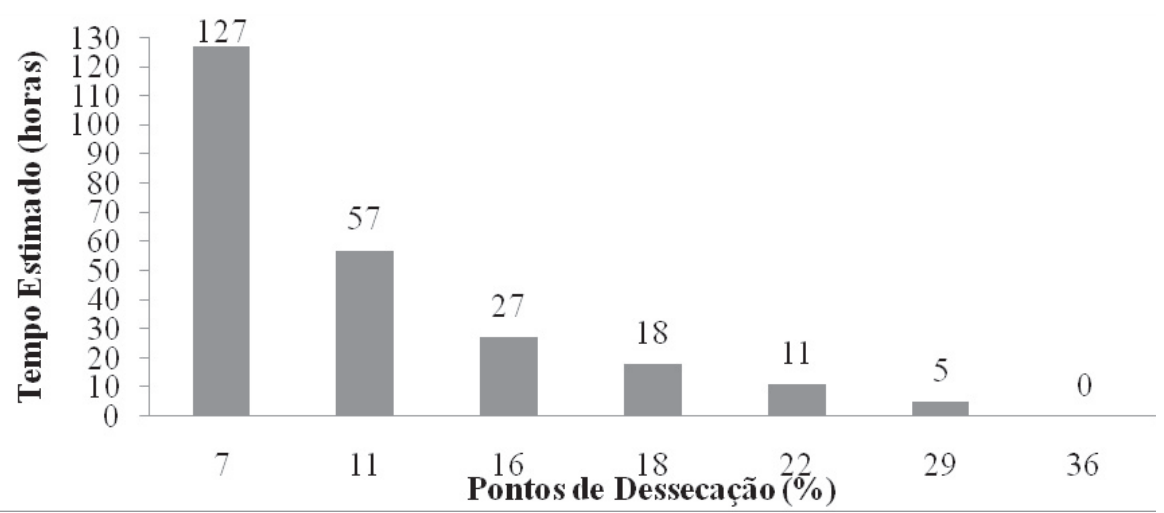

FIGURA 1- Secagem de sementes de Achras sapota até atingir 7\% de teor de água, UESC-Ilhéus-BA. 


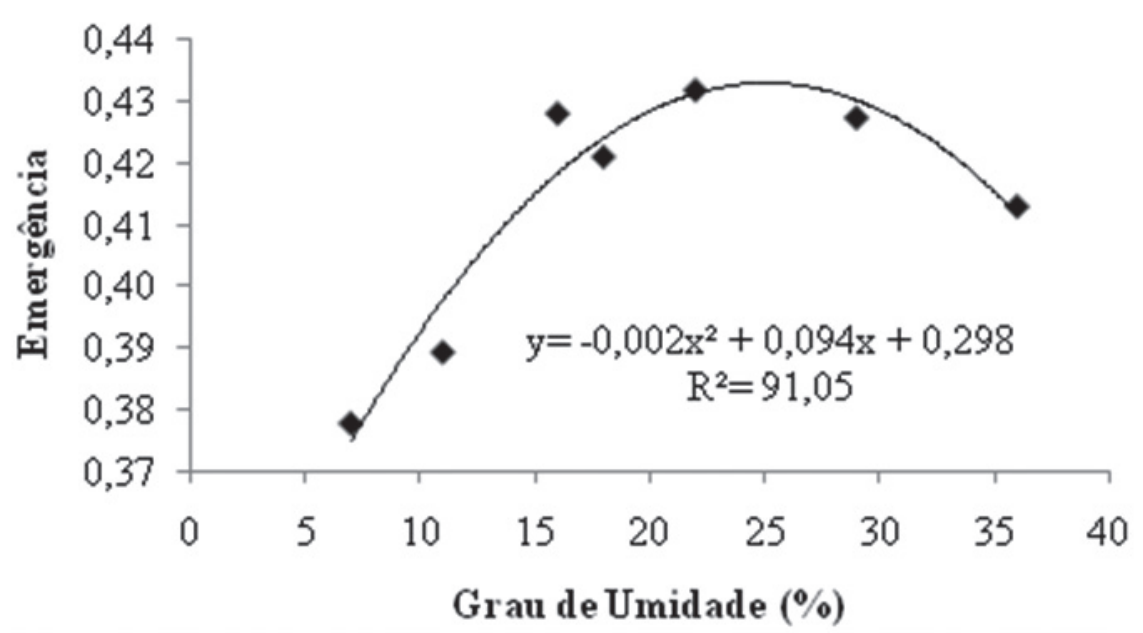

FIGURA 2- Emergência de plântulas (\%) de sementes de Achras sapota com diferentes graus de umidade, UESC-Ilhéus-BA. Cada ponto no gráfico representa a média de cada tratamento; e as barras, o erro-padrão.

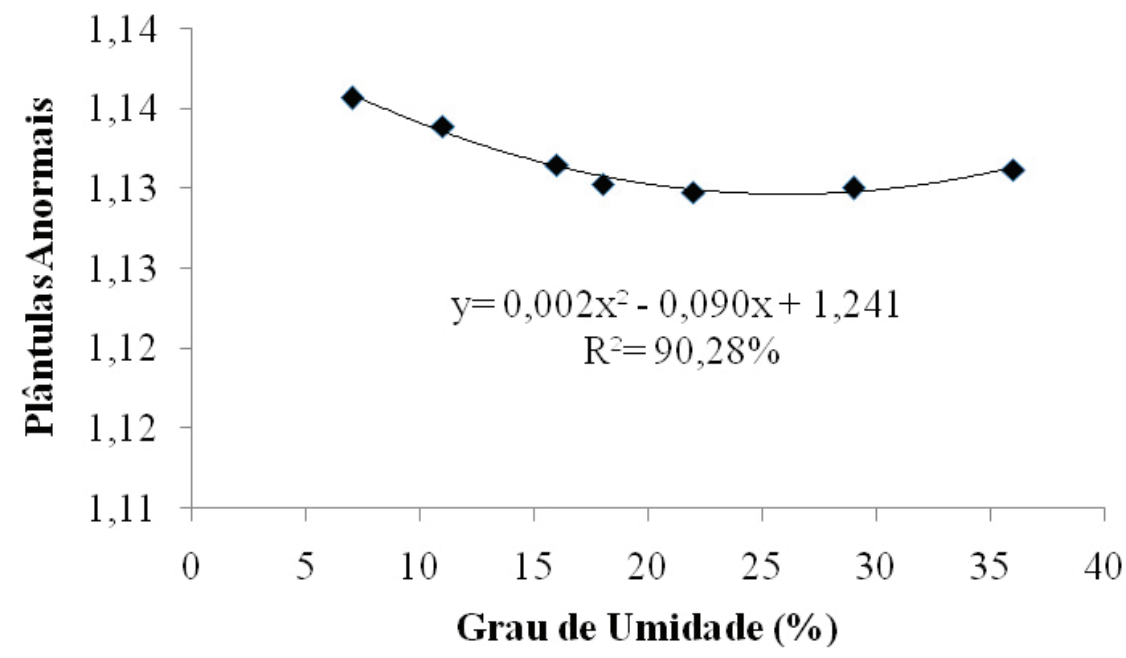

FIGURA 3- Plântulas anormais (\%) de sementes de Achras sapota com diferentes graus de umidade, UESC-Ilhéus-BA. Cada ponto no gráfico representa a média de cada tratamento; e as barras, o erro-padrão. 


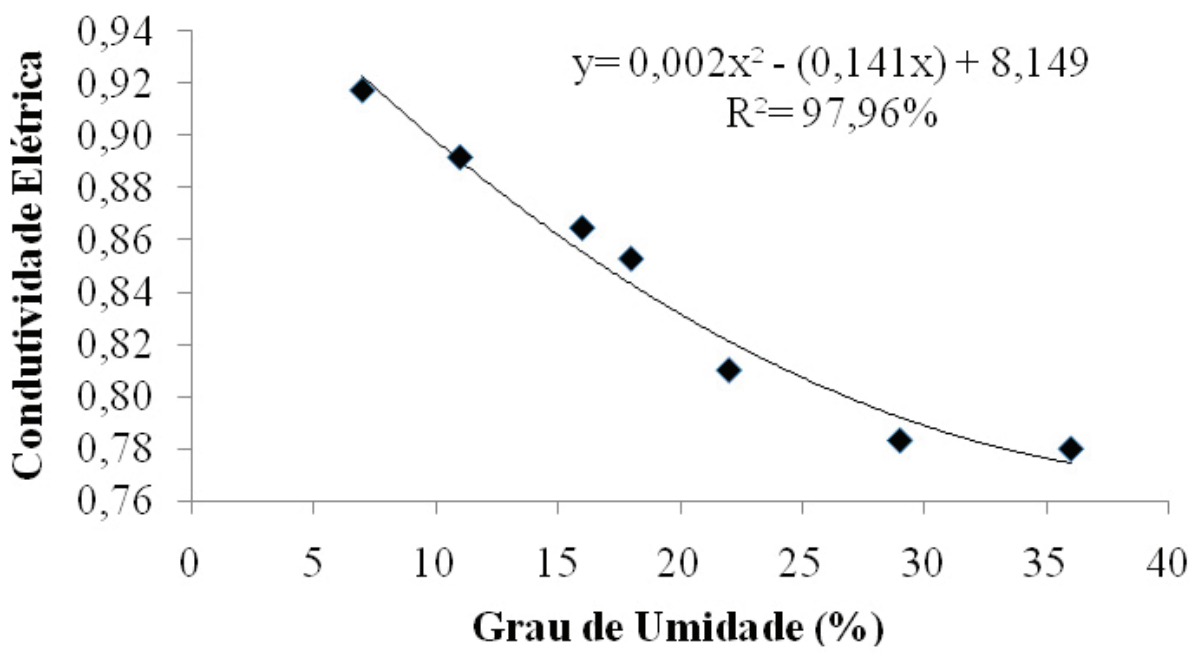

FIGURA 4- Condutividade elétrica da solução de sementes de Achras sapota com diferentes graus de umidade, UESC-Ilhéus-BA. Cada ponto no gráfico representa a média de cada tratamento; e as barras, o erro-padrão.

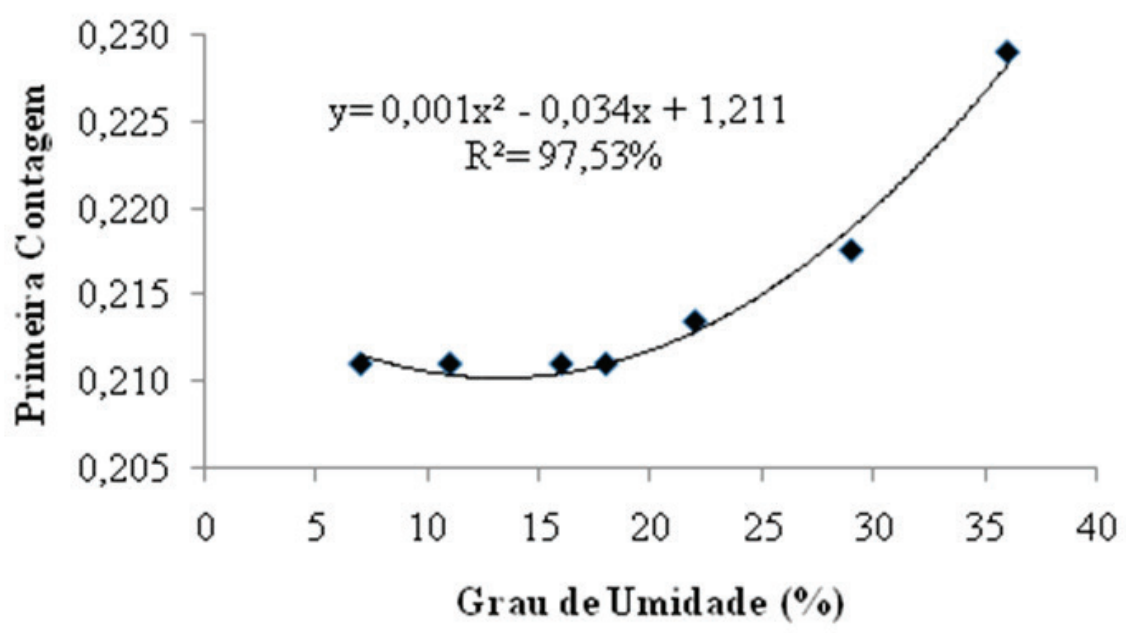

FIGURA 5- Primeira contagem do teste de emergência (\%) em sementes de Achras sapota com diferentes graus de umidade,, UESC-Ilhéus-BA. Cada ponto no gráfico representa a média de cada tratamento; e as barras, o erro-padrão. 


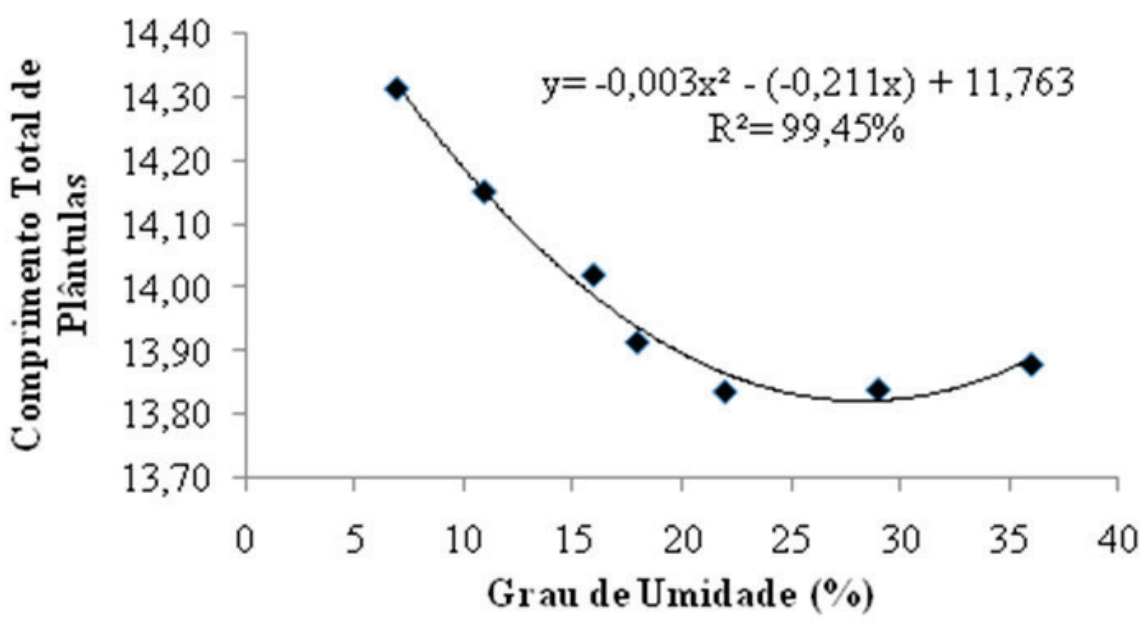

FIGURA 6- Comprimento de plântulas (cm.plântula- $\left.{ }^{1}\right)$ de Achras sapota, oriundas de sementes com diferentes graus de umidade, UESC-Ilhéus-BA. Cada ponto no gráfico representa a média de cada tratamento; e as barras, o erro-padrão.

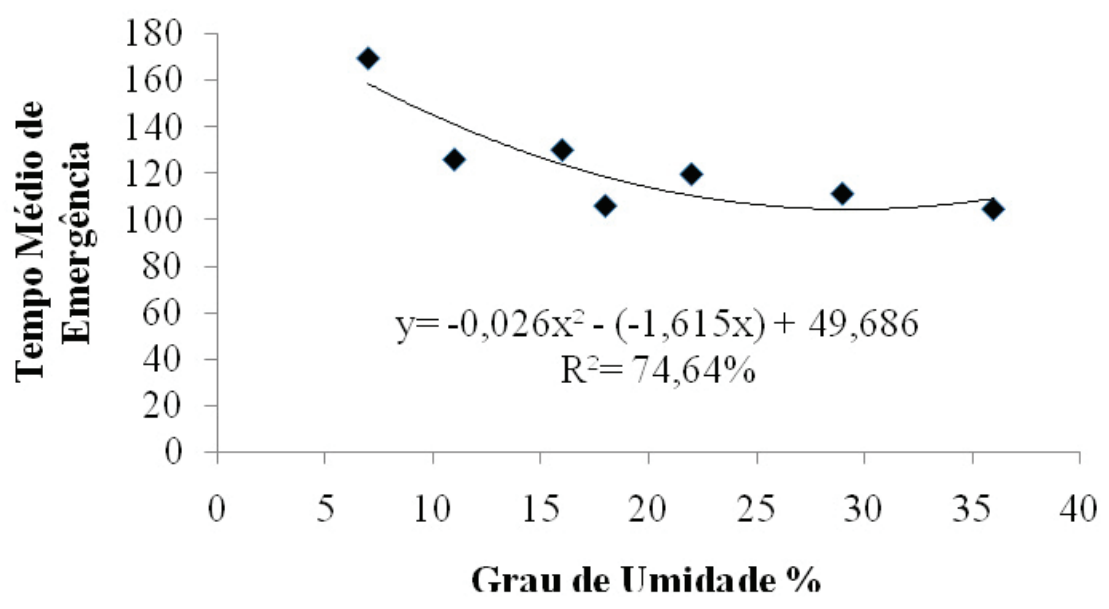

FIGURA 7- Tempo médio de emergência (dias) de Achras sapota, oriundas de sementes com diferentes graus de umidade, UESC-Ilhéus-BA. Cada ponto no gráfico representa a média de cada tratamento; e as barras, o erro-padrão. 
TABELA 1-Estimativa dos coeficientes de correlação simples de Pearson (r) das variáveis estudadas em sementes de Achras sapota, submetidas à dessecação, UESC-Ilhéus-BA.

\begin{tabular}{cccc}
\hline VARIÁVEIS & $\mathbf{C E}$ & $\mathbf{C P}$ & TME \\
\hline $\mathbf{G U}$ & $-0,93^{* *}$ & $-0,54^{* *}$ & $-0,75^{* *}$ \\
$\mathbf{C E}$ & & $0,62^{* *}$ & $0,75^{* *}$ \\
$\mathbf{C P}$ & & & $0,46^{*}$
\end{tabular}

Condutividade Elétrica (CE), Comprimento de Plântulas (CP), Massa Seca de Plântula (MST) e Tempo Médio de Emergência (TME). Coeficiente de correlação $(\mathrm{r})$ significativo a $1 \%(* *), 5 \%(*)$ de probabilidade e $\left({ }^{\text {ns }}\right)$ não significativo.

TABELA 2- Resultados do teste de Kruskal-Wallis das variáveis estudadas em sementes de Achras sapota, submetidas à dessecação, UESC-Ilhéus-BA.

\begin{tabular}{cc}
\hline VARIÁVEIS & p-value \\
\hline PC & 0,0022 \\
E & 0,0016 \\
PA & 0,0042 \\
MST & 1,0000 \\
\hline
\end{tabular}

Condutividade Elétrica (CE), Emergência (E), Plântulas Anormais (PA), Primeira Contagem do Teste de Emergência (PC), Comprimento de Plântula (CP), Massa Seca de Plântulas (MST) e Tempo Médio de Emergência (TME). Margem de erro: 5\% de probabilidade.

\section{CONCLUSÕES}

As sementes de Achras sapota L. podem ser dessecadas até atingirem o teor de água de $16 \%$ sem comprometimento da viabilidade das sementes e do desenvolvimento de plântulas normais.

\section{AGRADECIMENTOS}

À CAPES, pela concessão da bolsa.

\section{REFERÊNCIAS}

BRASIL. Ministério da Agricultura, Pecuária e Abastecimento. Manual de análise sanitária de sementes. Brasília: ACS, 2009. 200 p.

CABRAL, J. S. R.; SALLES, J. de F. ; SILVA, F. G.; BRANQUINHO, A. de C.; OLIVEIRA, R. C. de; Physiological quality of guapeva (Pouteria gardneriana Radlk.) seeds during storage. Global Science and Technology, Rio Verde, v.6, n.1, p.127133, 2013. Disponível em: <http://www.cefetrv. edu.br/periodicos/index.php/gst/article/view/484>. Acesso em: 9 ago. 2014.

CROMARTY, A.S.; ELLIS, R.H.; ROBERTS, E.H. Designing of seed storage facilities for genetic conservation. Rome: IPGRI, 1985. 100 p.
CRUZ, E. D.; CARVALHO, J. E. U. Biometria de frutos e sementes e germinação de curupixá (Micropholis cf. venulosa MART. \& EICHLER Sapotaceae). Acta Amazônia, Manaus, v.33, n.3, p.389-398, 2003. Disponível em: <file:///D:/Artigo/ CRUZ\%3B\%20CARVALHO\%202003.pdf $>$. Acesso em: 9 ago. 2014.

FARRANT, J.M. Editorial: special issue GROW "plant desiccation stress". Plant Growth Regulator, Dordrecht, v.62, p.189-191, 2010. Disponível em: <http://link.springer.com/content/ pdf $/ 10.1007 \% 2$ Fs $10725-010-9514-p d f>$. Acesso em: 18 maio 2013.

FERREIRA, A. G.; BORGHETTI, F. Germinação: do básico ao aplicado. Porto Alegre: Artmed, 323 p., 2004.

GOMES, R. P. Fruticultura brasileira. 13.ed. São Paulo: Nobel, 2007. p.395-399.

HONG, T. D.; ELLIS, R. H. A protocol to determine seed storage behaviour. Ipgri Technical Bulletin, Rome, v.1, p.38-39, 1996. Disponível em: $\leq \mathrm{http}: / /$ books.google.com.br/books $>$. Acesso em: 10 maio 2012.

KRZYZANOWSKI, F. C.; VIEIRA, R. D.; FRANÇA NETO, J. de B. Vigor de sementes: conceitos e testes. Londrina: ABRATES, 1999. 218 p. 
MARTINS, C. C.; NAKAGAWA, J.; BOVI, M. L. A. Avaliação da qualidade fisiológica de sementes de açaí. Revista Brasileira de Fruticultura, Jaboticabal, v.31, n.1, p.231-235, 2009. Disponível em: $<$ http://www.scielo.br/pdf/rbf/v31n1/v31n1a32. pdf $>$. Acesso em: 04 maio 2012.

MASETTO, T. E.; FARIA, J.M..R.; DAVIDE, A. C.; SILVA, E. A. A. da; 1. Desiccation tolerance and dna integrity in Eugenia pleurantha O. Berg. (Myrtaceae) seeds. Revista Brasileira de Sementes, Viçosa, MG, v.30, n.2, p.51-56, 2008. Disponível em: $<$ http://www.scielo.br/pdf/rbs/v30n1/a22v30n1. pdf $>$. Acesso em: 11 maio 2012.

NASCIMENTO, W.M.O.; CÍCERO, S.M.; NOVEMBRE, A.D.L.C. Conservação de sementes de açaí (Euterpe oleracea Mart.). Revista Brasileira de Sementes, Viçosa, MG, v.32, n.1, p.24-33, 2010. Disponível em: $<$ http://www.scielo.br/pdf/rbs/v32n1/ v32n1a03.pdf $>$. Acesso em: 07 maio 2012.

OLIVEIRA, L. M.; SILVA, E. O.; BRUNO, R. L. A.; ALVES. E. U.; Períodos e ambientes de secagem na qualidade de sementes de Genipa americana L. Semina: Ciências Agrárias, Londrina, v. 32, n. 2, p. 495-502, 2011. Disponível em: <http://www. uel.br/revista/uel/index.php/semagrarias/article/ view/3521/8409>. Acesso em: 11 maio 2012.

PRITCHARD, H.W.; WOOD, C.B.; HODGES, S.; VAUTIER, H.J. 100-seed test for desiccation tolerance and germination: a case study on eight tropical palm species. Seed Science and Technology, Zurichm v.2, n.32, p.393-403, 2004. Disponível em: $\leq \mathrm{http}: / /$ www.seedtest.org $>$. Acesso em: 18 maio 2013.
SANTOS, P. C. G.; SANTOS, P. C. G.; ALVES, E. U.; GUEDES, R. S.; SILVA, K. B.; CARDOSO, E. A.; LIMA, C. R. Qualidade de sementes de Hancornia speciosa Gomes em função do tempo de secagem. Semina: Ciências Agrárias, Londrina, v.31, n.2, p.343-352, 2010. Disponível em: $<\underline{\text { http:// }}$ www.uel.br/revista/uel/index.php/semagrarias/ article/view/5299/4823 > . Acesso em: 12 maio 2012.

STEINER, F. Comparação entre métodos para a avaliação do vigor de lotes de sementes de triticale. Ciência Rural, Santa Maria, v.41, n.2, p.200-204, 2011. Disponível em: $\leq \mathrm{http}: / /$ www.scielo.br/pdf/ cr/2011nahead/a875cr3844.pdf $>$. Acesso em: 13 maio 2012.

TOKUHISA, D.; SEDOYAMA, C.A.Z.; HILST, P.C.; DIAS, D. C. F. S. Teste de condutividade elétrica para avaliação da qualidade fisiológica de sementes de mamão (Carica papaya L.). Revista Brasileira de Sementes, Viçosa, MG, v.31, n.2, p.137-145, 2009. Disponível em: $\leq$ http://www. scielo.br/pdf/rbs/v31n2/v31n2a16.pdf $>$. Acesso em: 12 maio 2012.

VIEIRA, R.D.; CARVALHO, N.M de. Testes de vigor em sementes. Jaboticabal: FUNEP/UNESP, 1994. $164 \mathrm{p}$.

WALTERS, C. Levels of recalcitrance in seeds. Revista Brasileira de Fisiologia Vegetal, Londrina, n.12, p. 7-21, 2000. Edição especial.

ZUCARELLI, V.; BONJOVANI, M. R.; CAVARIANI, C.; NAKAGAWA, J. Tolerância à dessecação e influência do tegumento na germinação de sementes de citrumelo 'swingle' (Citrus paradisi MACF X Poncirus trifoliata (L) RAF.). Revista Brasileira de Fruticultura, Jaboticabal, v.31, n.1, p.291-295, 2009. Disponível em: $<$ http://www.scielo. br/pdf/rbf/v31n1/v31n1a42.pdf >. Acesso em: 15 maio 2012. 